\title{
Solvent free selective silylation of alcohols, phenols and naphthols with HMDS catalyzed by H- $\beta$ zeolite
}

\author{
Vasudha H. Tillu, Vinod H. Jadhav, Hanumant B. Borate, and Radhika D. Wakharkar* \\ Division of Organic Chemistry: Technology, National Chemical Laboratory, \\ Pune - 411 008, India \\ E-mail: rdw@dalton.ncl.res.in
}

(received 19 May 04; accepted 03 Sept 04; published on the web 09 Sept 04)

\begin{abstract}
Trimethylsilylation of alcohols, phenols and naphthols using HMDS catalyzed by commercially available $\mathrm{H}-\beta$ zeolite under solvent free conditions has been presented. The heterogeneous reaction conditions provided environmentally friendly protocol.
\end{abstract}

Keywords: HMDS, silylation, phenols, alcohols, naphthols, H- $\beta$ zeolite, solvent-free

\section{Introduction}

Trimethylsilylation of organic compounds ${ }^{1,2}$ having labile hydrogen atoms is an important organic transformation. It is a frequently used protection method in multistep synthesis of natural products due to the enhanced stability under a variety of conditions, solubility in non-polar solvents, thermal stability and the ease of removal which is simply accomplished by acid or base induced hydrolysis giving only unreactive siloxane as byproduct. It is also used extensively for the derivatization of hydroxy compounds to increase their volatility for gas chromatography and mass spectrometry.

A wide variety of methods using silylating agents such as chlorotrimethylsilane and base, ${ }^{3}$ bis-(trimethylsilyl)trifluoro acetamide, ${ }^{4}$ allyl silanes with acid, ${ }^{5}$ and bistrimethylsilyl ether, ${ }^{6}$ have been reported for silylation. However, these reagents require addition of bases and the difficulty in removal of amine salts formed from the acid byproduct and the base added is frequently encountered. Moreover, longer reaction time is an additional disadvantage of these reagents. To enhance the rate of reaction, in situ generated $\mathrm{TMSOTf}^{7}$ is used for silylation in the presence of base. However, the in situ preparation of TMSOTF requires the use of triflic acid, thus making the process expensive and environmentally hazardous. 1,1,1,3,3,3-Hexamethyldisilazane (HMDS) is a stable commercially available substitute for trimethylsilylation of hydrogen-labile substrates giving ammonia as the only byproduct. Silylation using this silazane type reagent is nearly neutral and does not need special precautions and products are separated from excess 
HMDS using simple techniques. However, the low silylating power of HMDS is a main drawback for its application, which needs forceful conditions and long reaction times in many instances. Hence, a variety of catalysts such as trimethylsilyl chloride ${ }^{8}$, sulfonic acids, ${ }^{9} \mathrm{ZnCl}_{2}{ }^{10}$ nitrogen ligand complexes of metal chlorides, ${ }^{11}$ zirconium sulfophenyl phosphonate, ${ }^{12}$ yttrium based Lewis acid, ${ }^{13}$ montmorillonite $\mathrm{K}-10,{ }^{14}$ Envirocat EPZGOO ${ }^{15}$ and special types of catalysts having the general formula $\mathrm{X}^{1}-\mathrm{NH}-\mathrm{X}^{16}$ have been reported for the silylation using HMDS. The most convenient protocol for laboratory scale derivatisation accepted as green technology appeared recently, ${ }^{17}$ using microwave irradiation under solvent-free conditions.

In the present communication we wish to report efficient solvent free silylation of alcohols, phenols and naphthols with HMDS catalyzed by commercially available H- $\beta$ zeolite providing heterogenous reaction conditions.

$$
\begin{aligned}
& \mathrm{R}-\mathrm{OH}+\mathrm{HMDS} \underset{80^{\circ} \mathrm{C}}{\stackrel{\mathrm{H} \text {-beta zeolite }}{\longrightarrow} \text { R-OTMS }} \\
& \mathrm{R}=\text { primary, secondary and tertiary alkyl, } \\
& \text { aryl and cyclohexyl. }
\end{aligned}
$$

\section{Scheme 1}

\section{Results and Discussion}

Initially we conducted blank experiments without the H- $\beta$ zeolite as the catalyst and found the reactions to be sluggish $(\sim 7-15 \mathrm{~h})$. Silylation of m-cresol without catalyst yielded only $25 \%$ of the product in 4 hours. Silylation of phenol and benzyl alcohol using HMDS in toluene at ambient temperature in presence of $\mathrm{H}-\beta$ zeolite $(10 \% \mathrm{w} / \mathrm{w})$ took about $10 \mathrm{~h}$ and $5 \mathrm{~h}$ for completion respectively. The same experiments were repeated at $70-80^{\circ} \mathrm{C}$ to afford the corresponding products in comparable yield in more or less the same time period. However, neat reaction without any solvent enhanced the yield in much shorter duration and the derivatization was complete in $\sim 1.5 \mathrm{~h}$.

The selectivity and versatility of the thermal solvent-free recipe was further confirmed by application of the general procedure given below for various examples shown in Table 1 . In a typical general procedure, a neat mixture of hydroxy compound, HMDS and $10 \%(\mathrm{w} / \mathrm{w}) \mathrm{H}-\beta$ zeolite was heated at $80^{\circ} \mathrm{C}$ until the reaction was complete (TLC). After completion of reaction, ethyl acetate was added and catalyst filtered. The filtrate was concentrated and pure product was obtained either by distillation under reduced pressure or by column chromatography on neutral alumina.

A wide range of structurally diverse and functionalized alcohols, phenols and naphthols underwent silylation by this procedure to provide the corresponding TMS ethers in excellent isolated yields as shown in Table 1, whereas amines (Table 1, entries 14, 19, 20) and thiol (Table 1 , entry 21) remained unaffected under the reaction conditions. 
Table 1. H- $\beta$ zeolite catalyzed selective protection of alcohols and phenols as their silyl ethers

\begin{tabular}{|c|c|c|c|c|c|c|}
\hline $\begin{array}{l}\text { Entry } \\
\text { No. }\end{array}$ & Substrate & $\begin{array}{l}\text { Subs./ } \\
\text { HMDS } \\
\text { ratio }\end{array}$ & $\begin{array}{l}\text { Stirring in } \\
\text { Time }(\mathrm{h})\end{array}$ & $\begin{array}{l}\text { Toluene at r.t. } \\
\text { Yield }^{\mathbf{a}_{0}}\end{array}$ & $\begin{array}{l}\text { Heating a } \\
\text { Time (h) }\end{array}$ & $\begin{array}{l}\text { C without solvent } \\
\text { Yield }^{\mathrm{a}} \%\end{array}$ \\
\hline 1 & n-Octanol & $1: 0.6$ & 8 & 96 & 1.3 & 98 \\
\hline 2 & $\mathrm{MeOOC}-\left(\mathrm{CH}_{2}\right)_{6}-\mathrm{CH}_{2} \mathrm{OH}$ & $1: 0.6$ & 8 & 96 & 1.5 & 95 \\
\hline 3 & Allyl alcohol & $1: 0.6$ & 7 & 97 & 1.5 & 98 \\
\hline 4 & $\mathrm{OH}$ & $1: 0.6$ & 15 & 85 & 2.5 & 96 \\
\hline 5 & Cyclohexanol & $1: 1$ & 12 & 95 & 2.0 & 98 \\
\hline 6 & tertiary-Butanol & $1: 0.6$ & 30 & 45 & 2.5 & 70 \\
\hline 7 & Benzyl alcohol & 1:0.6 & 5 & 95 & 1.3 & 97 \\
\hline 8 & & $1: 1.5$ & 9 & 91 & 1.5 & $95^{\mathrm{b}}$ \\
\hline 9 & Phenol & $1: 0.75$ & 10 & 87 & 1.5 & 90 \\
\hline 10 & resorcinol & $1: 1.5$ & 10 & 76 & 1.5 & $89^{\mathrm{b}}$ \\
\hline 11 & meta-Cresol & $1: 1.0$ & 12 & 76 & 1.7 & 91 \\
\hline 12 & $\alpha$ - Naphthol & $1: 0.75$ & 12 & 67 & 2.5 & 90 \\
\hline 13 & $\beta$ - Naphthol & $1: 1$ & 20 & 67 & 2.5 & 89 \\
\hline 14 & & $1: 1$ & 15 & 92 & 2.0 & $92^{\mathrm{c}}$ \\
\hline 15 & & $1: 0.75$ & 15 & 80 & 2.0 & 91 \\
\hline 16 & & $1: 1$ & 13 & 79 & 1.5 & 92 \\
\hline 17 & & $1: 1$ & 14 & 85 & 1.7 & 92 \\
\hline 18 & Furfuryl alcohol & $1: 1$ & 10 & 83 & 1.3 & 92 \\
\hline 19 & Aniline & $1: 0.75$ & 5.0 & - & 30 & - \\
\hline 20 & Benzylamine & $1: 0.75$ & 5.0 & - & 30 & - \\
\hline 21 & Thiophenol & $1: 0.75$ & 5.0 & - & 30 & - \\
\hline
\end{tabular}

${ }^{a}$ Isolated yield, confirmed by comparison with IR and ${ }^{1} \mathrm{H}$ NMR spectra of authentic samples.

${ }^{\mathrm{b}}$ Disilyl ethers obtained.

${ }^{\mathrm{c}}$ Selectively 2-trimethylsilyloxy aniline was obtained. 
Table 1 also displays a comparison of the results obtained by silylation at room temperature in toluene with those carried out under solvent-free conditions at elevated temperature. It is noteworthy from Table 1 that primary alcohols were silylated more easily than secondary alcohols and phenols. Tertiary alcohols however gave low yields.

Heating increased the rate of reaction, reducing the reaction time from several hours to 1 to $1.5 \mathrm{~h}$ and obviated the need for solvent. The efficacy of $\mathrm{H}-\beta$ zeolite as a catalyst can be clearly visualized in the case of unsaturated alcohols (Entries 3 and 4) and the corresponding silyl ethers are obtained in excellent yields. After the reaction, the catalyst was recovered with retention of its catalytic activity. It can be further reactivated for reuse by heating at $100^{\circ} \mathrm{C}$ in presence of air.

\section{Conclusions}

The present solvent free procedure provides a selective protection of a hydroxyl group in the presence of amines and thiols. This method has the advantage of simplicity in operation and mild reaction conditions tolerable to acid sensitive functionalities, cost efficiency, increased yields and environment friendliness compared to its homogeneous counterpart. The observed efficient performance of H- $\beta$ zeolite may be attributed to its large pore opening, three dimensional channel system and the high concentration of acid sites. The re-usability of the catalyst makes this method cost-efficient. Moreover, this protocol introduces a practical and viable green technology of solvent-free silylation of alcohols.

\section{Experimental Section}

General Procedures. Commercially available alcohols, amines and thiols were distilled before use. HMDS was purified by fractional distillation. $\mathrm{H}-\beta$ zeolite was procured as a gift from United Catalyst India Ltd. (UCIL) Mumbai, $\mathrm{SiO}_{2} / \mathrm{Al}_{2} \mathrm{O}_{3}-30$, surface area $-700 \mathrm{~m}^{2} / \mathrm{g}$, pore diameter $=$ $7.6 \times 6.4 \mathrm{~A}^{\circ}$. Prior to use, it was calcined at $110^{\circ} \mathrm{C}$ for $2 \mathrm{hrs}$. Infrared spectra were recorded on an ATI-MATTSON RS-1FT-IR spectrometer. ${ }^{1} \mathrm{H}$ NMR spectra were recorded on a Bruker AC200 spectrometer.

\section{Typical procedure for silylation in toluene}

A mixture of n-octanol $(1 \mathrm{mmol})$, HMDS $(0.6 \mathrm{mmol})$ and $\mathrm{H}-\beta$ zeolite $(10 \% \mathrm{w} / \mathrm{w})$ in toluene $(10 \mathrm{ml})$ was stirred at room temperature and the reaction progress was monitored by TLC. Complete conversion was observed after eight hours when the catalyst was filtered off and the solvent was removed under reduced pressure. The residue obtained was passed through a column of neutral alumina to collect the trimethylsilyloxyoctane as a colourless liquid (96\%). The product was characterized by IR and NMR spectroscopy. 
${ }^{1} \mathrm{H}-\mathrm{NMR}\left(\mathrm{CDCl}_{3}\right): \delta: 0.06(\mathrm{~s}, 9 \mathrm{H}), 0.089(\mathrm{t}, 3 \mathrm{H}), 1.28(\mathrm{~m}, 10 \mathrm{H}), 1.52(\mathrm{t}, 2 \mathrm{H}) . \quad \mathrm{IR}\left(\mathrm{CHCl}_{3}\right)$ : 2858.35, 2957.18, 2930.26, 1252.62, 1215.83, 833.55, 760.18, 581.12, 463.05, 411.73, 422.70, $433.72,447.87 \mathrm{~cm}^{-1}$.

\section{Typical procedure for the preparation of trimethyl silyloxy octane at $80^{\circ} \mathrm{C}$}

A neat mixture of n-octanol $(1 \mathrm{mmol})$, HMDS $(0.6 \mathrm{mmol})$ and $\mathrm{H}-\beta$ zeolite $(10 \% \mathrm{w} / \mathrm{w})$ was heated at $80^{\circ} \mathrm{C}$ for $1.3 \mathrm{~h}$. After completion of reaction (monitored by TLC), ethyl acetate was added, reaction mixture filtered and filtrate concentrated. The product was then purified by column chromatography on neutral alumina to yield trimethyl silyloxyoctane as a colorless liquid (98\%). The product was characterized by IR and NMR spectroscopy (same as above).

The same procedure was followed for the preparation of all TMS ethers using H- $\beta$ zeolite at $80^{\circ} \mathrm{C}$ as listed in Table 1 . All the TMS ethers prepared in the present work are well known compounds and are easily identified by the IR, ${ }^{1} \mathrm{H}$ NMR spectra as well as boiling point comparison with the reported data.

\section{References}

1. (a) Greene, T. W.; Wuts, P. G. M. Protective Groups in Organic Synthesis, $3^{\text {rd }}$ Edn; Wiley \& Sons: New York, 1999, p.116. (b) Sartori, G.; Ballini, R.; Bigi, F.; Bosica, G.; Maggi, R.; Righi, P. Chem.Rev. 2004, 104, 199.

2. Cooper, B. E. Chem. Ind. 1978, 794 and references cited therein.

3. (a) West, R. J. Am. Chem. Soc. 1958, 80, 3246. (b) House, H. O.; Czuba, L. J.; Gall M.; Olmstead, H. D. J. Org. Chem. 1969, 34, 2324. (c) Corey, E. J.; Snider, B. B .J. Am. Chem. Soc. 1972, 94, 2549.

4. Chirakul, P; Hampton P. D.; Duesler, E. N. Tetrahedron Lett. 1998, 39, 5473.

5. Morita, T.; Okamoto Y.; Sakurai, H. Tetrahedron Lett. 1980, 21, 835.

6. Pinnick, H. W.; Bal B. S.; Lajis, N. H. Tetrahedron Lett. 1978, 4261.

7. Olah, G. A; Husain, A; Gupta, B. G. B; Salem G. F.; Narang, S. C. J. Org. Chem. 1981, 46, 5212.

8. Cossy, J.; Pale, P. Tetrahedron Lett. 1987, 28, 6039.

9. Boerner, D; Koerner, G; Spieker, F.; Wiemann, M .German Patent, 1978, DE 2757936.

10. Firouzabadi, H.; Karimi, B. Synth. Commun. 1993, 23, 1633.

11. Firouzabadi, H.; Sardarian, A. R.; Khayat, Z.; Karimi, B.; Tangestaninejad, S. Synth. Commun. 1997, 27, 2709.

12. Curini, M.; Epifano, F.; Marcotullio, M. C.; Rosati, O.; Costantino, U. Synth. Commun. 1999, 29, 541.

13. Kumar, P.; Pais G. C. G.; Keshavaraja, A. J. Chem. Research (S) 1996, 376.

14. Zhang, Z. H.; Li, T. S.; Yang, F.; Fu, C. G. Synth. Commun. 1998, 28, 3105. 
15. Bandgar, B. P.; Wadgaonkar, P. P. Synth. Commun. 1997, 27, 2069.

16. Bruynes, C. A.; Jurriens, T. K. Eur. Pat. 1982, EP 43630 A2

17. Mojtahedi, M. M.; Saidi, M. R.; Bolourtchian M.; Heravi, M. M. Phosphorus, Sulfur and Silicon and the Related Elements 2002, 177, 289 